\title{
References and Abbreviations
}

\section{Laycock Manuscripts and Published Works}

A Account of the Election of Dr Thomas Laycock to the Chair of the Practice of Medicine Edin University 1855 Autobiographical. In Thomas Storer Clouston and Royal Edinburgh Asylum Papers, LHSC MS GD 16. In text: 'Account'.

J A Journal kept by Thomas Laycock from 1833 including the Time spent in London when a Medical Student, EUL MS Gen 1813. In text: 'Journal'.

E Chair of Physic in the University of Edinburgh. Evidence of professional acquirements submitted to the honourable patrons of the University of Edinburgh, .. . Part I. - Chronological catalogue of published writings. Part II. - 2 Testimonials, York, William Sotheran, 1855. In text: Evidence.

EC Chronological catalogue of the essays, reviews, and treatises in the various departments of the theory and practice of medicine, including pathology, pathological physiology, psychology, hygiene, medical police, and medical ethics, ... , York, W. Sotheran, 1855. In text: Catalogue.

ET Testimonials submitted to the honourable patrons of the University of Edinburgh, ...., York, William Sotheran, 1855. In text: Testimonials.

TND A treatise on the nervous diseases of women; comprising an inquiry into the nature, causes and treatment of spinal and hysterical disorders, London, Longman and others, 1840. In text: Treatise.

CS Correspondence and statements regarding the teaching of clinical medicine in the University of Edinburgh, 1855-1857; with an appendix, containing an examination of the allegations of Dr. Christison and Dr. Bennett, Edinburgh, R. and R. Clark, 1857. In Text: Correspondence and statements.

$\mathrm{S} \quad$ Sequel to correspondence and statements regarding the teaching of clinical medicine in the University of Edinburgh, 1855-57, Edinburgh, R. and R. Clark, 1857. In text: Sequel.

MB Mind and brain: or, the correlations of consciousness and organisation; with their applications to philosophy, zoology, mental pathology, and the practice of medicine, 1st ed., Edinburgh, Sutherland and Knox, 1860; 2nd ed., Edinburgh, Sutherland and Knox, 1869. In text: Mind and brain.

MOR [Lectures on] The principles and methods of medical observation and research for the use of advanced students and junior practitioners, 1st ed., Edinburgh, 
Adam and Charles Black, 1856; 2nd ed., Maclachlan and Stewart, 1864. In text: Medical observation.

\section{Manuscript Collections}

BL The British Library

RCPE Royal College of Physicians of Edinburgh Library

RCSE Royal College of Surgeons of Edinburgh Library

ECA Edinburgh City Archives

EUL Edinburgh University Library

LHSC Lothian Health Services Collection, EUL

NLS National Library of Scotland

SRO Scottish Record Office

UCL University College London Library 